This document is the accepted manuscript version of the following article:

Fischer, M., Angst, M., \& Maag, S. (2019). Co-participation in the Swiss water forum network. International Journal of water Resources Development, 35(3), 446-464. https://doi .org/10.1080/07900627.2017.1374929

\title{
Co-Participation in the Swiss Water Forum Network
}

Paper resubmitted to the International Journal of Water Resources Development, Special Issue on "Understanding emergent participation practices in water governance"

Manuel Fischer, Environmental Social Science Department, Swiss Federal Institute of Aquatic Science and Technology (Eawag), Überlandstrasse 133, CH-8600 Dübendorf, Switzerland; Institute of Political Science, University of Berne, Switzerland. manuel.fischer@eawag.ch.

Mario Angst, Environmental Social Science Department, Swiss Federal Institute of Aquatic Science and Technology (Eawag), Überlandstrasse 133, CH-8600 Dübendorf, Switzerland.

Simon Maag, Environmental Social Science Department, Swiss Federal Institute of Aquatic Science and Technology (Eawag), Überlandstrasse 133, CH-8600 Dübendorf, Switzerland.

***Thanks go to Benjamin Leathley for data preparation. 


\begin{abstract}
In polycentric governance systems, actors interact in different venues, such as forums which foster cross-sectoral interaction. This analysis centers on water forums in Switzerland and on actors with multiple forum memberships creating interactions throughout the entire forum network. Findings show that the central actors within the entire water forum network are predominantly from the public administration sector, even though members from the private sector are most numerous. Despite an emphasis on the bottom-up and self-organizing character of polycentric governance systems in the literature, this analysis shows that public administration actors still play a crucial role as network managers and brokers.
\end{abstract}

Keywords: Water governance, polycentric governance, forums, participation, actors, networks.

\title{
Word count: 8163
}




\section{Introduction}

Water governance concerns many different actors from public administration, the private sector, and the scientific community. Sustaining interactions between actors from these different sectors is complicated, as they have different logics of internal organization, different professional languages, different roles in a governance system, different values and interests, and different demands with respect to their use of water (Huxham et al. 2000; Moss and Newig 2010; Tortajada 2010a; Crona and Parker 2012; Edelenbos and Teisman 2013; Van Meerker et al. 2014). For example, whereas environmental protection associations fight for the vital state of rivers, municipalities use the same river for energy production, or to protect their populations from flooding risks. National-level public administration actors want to make sure international treaties are respected, while regional administration actors strive for the effective implementation of revitalization projects. At the same time, scientific actors may want to gather data on water quality or call attention to future risks to water quality.

Forums are specific types of venues in polycentric governance systems that explicitly foster interactions between actors from these different sectors (Fischer and Leifeld 2015). Interactions between actors from the public administration, the private sector, and the scientific community are important for exchange of information, coordination among actors, or resolution of conflicts (Tortajada 2010a; Edelenbos and Van Meerkerk 2015). This article analyzes the types of actors that participate in forums, and their contributions to interactions within and across forums. The analysis focuses on water governance and water forums in Switzerland. Given the relatively limited resources of Swiss public administration actors, compared to international standards (Sciarini et al. 2015), forums are crucial for fostering the exchange of knowledge and information between public administration, the private sector, and the scientific community.

This analysis makes at least three contributions to our understanding of polycentric governance systems and the roles that forums and different types of actors play within such 
systems. First, and particularly relevant for the theme of this special issue, the article presents forums as a specific type of venue which fosters interactions between public administration actors, private sector actors, and scientific organizations for the governance of water-related issues. Second, the analysis emphasizes the importance of observing not only individual water forums, but the entire network of forums. This scope is crucial because individual forums usually connect actors only with respect to certain sub-aspects of the much broader watergovernance issue. Therefore, the literature on polycentric governance (Ostrom 2010) and the ecology of games (Lubell 2013) emphasizes the importance of taking into account the entire governance system, including the many forums and many different actors dealing with different water-related issues. Following this reasoning, the current study covers a network of 23 forums and over 300 actors in the Swiss water governance sector. Third, the analysis shows that even though public administration actors are clearly outnumbered by private sectors actors, they are highly central because they connect the different water forums with each other. The current paper thus contributes to the body of knowledge on the changing role of public administration actors in governance systems by presenting one way in which they play bridging and network management roles.

The remainder of this article is organized as follows. The theory section summarizes arguments on polycentric governance systems and the ecology of games approach, defines forums, and explains the importance of focusing on networks of forums. The empirical section presents a unique dataset on Swiss water forums and actors that are members of these forums. The analysis first describes the different types of forums in terms of their size, composition, purpose, and outputs. It then focuses on the participation of actors in these forums, and models the entire network of Swiss water forums and its members. This second step is based on descriptive statistics as well as on a two-mode exponential random graph model for the statistical analysis of network data. The article ends with a discussion of the main results and their implications. 


\section{Theory}

\section{Polycentric governance systems}

In modern collaborative and polycentric governance systems (Ansell and Gash 2008; Ostrom 2010; Emerson et al. 2012), many different types of actors simultaneously interact, negotiate, and compete over various interrelated issues, taking decisions in many different venues within different jurisdictions and at different levels (Ostrom 2010; Lubell 2013). The participation of actors in these different venues creates a network of direct and indirect interactions and communication possibilities among actors dealing with given issues. Such a complex network of interactions across different venues is a key feature of polycentric governance systems, and is key to overcoming collective action problems and addressing complex issues such as climate change or the management of natural resources. Building on the basic idea of polycentric governance and the seemingly chaotic coexistence of venues, the ecology of games approach (Lubell 2013) stresses the importance of not only describing these networks, but also understanding actors' strategies as they make their choices between venues.

\section{Cross-sectoral interaction within forums}

Forums are a special type of venue within polycentric governance systems. They create a space for interactions among actors from different societal sectors such as public administration, the private sector, and the scientific community (Bates et al. 2013; Fischer and Leifeld 2015). By fostering repeated, institutionalized interactions between actors, forums can contribute to cross-sector coordination and collaboration. Cross-sector interactions are normally complicated by the fact that different societal sectors such as public administration, the private sector, and the scientific community have different types of internal organization, different roles in a policy domain, different perspectives on problems, as well as different professional languages (Huxham et al. 2000; Crona and Parker 2012). 
Among the three sectors distinguished in this article, public administration actors, including government actors, stand out for several reasons (Fischer 2016). Their decisions are considered binding in society, and are backed by the possibility of a legitimate use of force (Adam and Kriesi 2007). Given their formal responsibility, public administration actors have a crucial influence on the design of policy processes. Accordingly, they are often perceived as particularly powerful actors in policy networks (Fischer and Sciarini 2015; Ingold and Leifeld 2016). Furthermore, public administration actors often act as brokers between different coalitions, and therefore exert a particular form of influence in terms of finding compromises in policy making processes (Ingold 2011; Ingold and Varone 2012). Within forums, public administration actors can facilitate interactions between other forum members by providing critical resources such as knowledge or administrative capacity (Feldman and Khademian 2007; Emerson et al. 2012). Furthermore, public administration actors can cast a 'shadow of hierarchy' on forum interactions, that is, their presence can increase the legitimacy of forum interactions and related outputs (Sörensen and Torfing 2009).

Compared to the role of public administration actors, the specific function of actors from the private sector in the policy process is advocacy, with the aim of influencing policy processes in the direction of their specific goals. Accordingly, the private sector includes professional interest groups, business associations, civil society groups, public interest groups (Berry and Wilcox 2015), private firms, as well as individual persons. Of course, these different actors within the private sector defend very different positions on a given issue. However, we refer to them as private sector actors, as opposed to public administration or scientific actors, because they all have a similar role in the governance system: namely, influencing policy processes by advocating their interests and values (Dür and De Bièvre 2007, Dür and Mateo 2013).

The third sector considered here, the scientific community, tends to emphasize complexity over simple and clear solutions which are readily implementable in politics (Crona and Parker 
2012) and usually provides expertise without having a strong lobbying agenda. Given these different roles and functioning logics, establishing cross-sectoral interactions is a challenge. Forums contribute to addressing this challenge.

Forums contribute to a broad range of outputs, such as knowledge exchange among actors, the creation of a joint problem understanding, learning, and trust-building (Fischer and Leifeld 2015). Beyond that, many forums produce more tangible outputs such as position papers, policy recommendations, or implementation plans, therefore creating concrete inputs to policy-making processes (Ostrom 1990; Sörensen and Torfing 2009; Börzel and Risse 2010; Fischer and Leifeld 2015; Fischer and Schläpfer 2017). While specific access rules regulate participation in some forums, most forums are open to all actors with a stake in the issue the forum deals with. Actors therefore have significant freedom to choose strategically to participate in one or several forums (Lubell 2013).

\section{A forum network}

Interactions within a single forum are necessarily limited to a relatively small number of actors that are particularly interested in the issue of that forum. Yet, as stressed by the literatures on polycentric governance and the ecology of games (Ostrom 2010; Lubell 2013), the various forums and the actors participating therein together produce a network of forums. This network then creates the potential for indirect connections between a much larger number of actors that isolated forums would allow (Edelenbos and Van Meerkerk 2015). Actors which are members in several forums are central in this forum network, as they connect different parts of it. Centrality is a key concept in the analysis of networks It describes actors which are in some way - depending on the exact definition of centrality important in the network. The concept of 'two-mode brokerage' (Jasny and Lubell 2015) refers to a specific type of centrality that characterizes actors which are members in two different forums and therefore create an indirect connection between members of the two 
forums. If two-mode brokers exist in a network of forums, then other actors can connect even without being in direct contact within a specific forum.

Obviously, presence in the same forum does not mean that actors automatically coordinate or collaborate. However, forums create spaces for communication and interaction, which in turn have been shown to positively influence collaboration among actors (Leifeld and Schneider 2012; Fischer and Sciarini 2016).

\section{Case, data and methods}

\section{Water policy in Switzerland}

In federalist and consensus-oriented Switzerland, competences related to water are distributed across three levels of government, and among multiple agencies (Lijphart 1999; Sciarini et al. 2015). Water-related competences at the national level have increased since the end of the $19^{\text {th }}$ century when the federal government started to assume water-related competences from the constituent states (the cantons). Over time, the federal government has formulated general principles on flood protection, fisheries, water-related land use and planning, and hydropower. Issues of water protection and quality are more recent competences at the level of the federal government. The regional governments, i.e. the Cantons, are responsible for the implementation of federal laws, but often benefit from high flexibility and financial compensations from the federal budget. Cantons also remain the formal owners of their water bodies (Mauch and Reynard 2004), and they mutually coordinate issues related to joint water bodies through inter-cantonal treaties without the involvement of the national government (Bochsler 2009).

Thus, water-related issues in Switzerland are discussed at several levels of decision-making, as well as across these levels. Accordingly, actors from all levels of government are represented in water forums. In general, Switzerland has an established system of consensus- 
oriented political integration between actors from public administration and the private sector (Sciarini et al. 2015).

\section{Identification of water forums}

The article focuses on Swiss forums that list the protection of, the protection from, or the use of water as their central issue on their webpage (see hyperlinks in Table 2 for the webpages of the forums). The selection of forums is based on their definition as organizations that include actors from different sectors. Specifically, an organization is considered a forum if its membership list includes at least one representative of at least two of the following three sectors: public administration including government and administrative actors from all levels, private actors including interest groups, individual firms as well as individual persons with no specific affiliation, and the scientific community. In addition, to qualify as a forum, the organization needs to be permanent, thus excluding temporary forums and single events. The sample is further limited to forums which operate at the national level (no local, regional, or international forums).

Based on this definition, two strategies were applied iteratively over several rounds in order to identify relevant forums: extensive document research and surveys among managers of forums. The first strategy, document research, started with the website of the Swiss Federal Office for Environment, where several relevant forums are listed. Drawing on the websites of these forums, we collected references to additional forums, and repeated this process until it yielded no new results. The second strategy, surveys among forum managers, relies on snowball sampling. Managers of all forums identified through the first strategy were contacted and asked to indicate other forums they were aware of. Their information served as a basis for another round of website research and two other waves of 'snowballing' among the managers of the newly identified forums. No new water forums were mentioned in the last round. 
Our final sample contains 23 water-related forums, which are listed in Table 2. The Principality of Liechtenstein is a member in one forum and is included in the category of public administration (cantons). One forum member represents a political party and was coded as a private actor. The case numbers in the first column are used in Figure 2 to label the forum-nodes in the network. Four forums have a multi-level structure. They consist of an umbrella steering committee, i.e. the 'main forum' and of working groups or committees, i.e. 'sub-forums'. Sub-forums are indented in Table 2. The different entities of these multi-level forums are considered as separate cases because they differ with respect to membership composition, thematic focus, and goals.

\section{A network of actor participation in forums}

For all 23 forums, a list of members was available from the website of the forum. These lists include not only the names of the individual persons but also the names of the collective actors they represent. For this study, collective actors rather than individual persons are treated as members of forums. In a governance system, individual persons usually act as representatives of collective actors. A small number of forum members without any affiliation to a collective actor were treated as individuals (see list of actors and their forum memberships in Table A1 in the appendix. Individuals are anonymized). Behind our decision to focus on collective actors rather than individuals lies the assumption that either collective actors send the same individual to all forums in which they participate or that there is a high level of internal communication. In cases where this assumption does not hold, the potential of forums to create coordination is limited.

The 23 Swiss water forums include a total of 342 actors which are members of at least one of the 23 forums. Overall, 10 actors are members in 5 forums, 12 are members in 4 forums, 22 are members in 3 forums, 61 are members in 2 forums, and 223 actors are members in only a single forum. Together, the network among the 23 forums and 342 actors can be formally 
represented by specifying the relationship between the mutually exclusive sets of actors $A$ and forums $F$ in a $(n, m)$ rectangular incidence matrix $(X)$ with $n$ equaling the number of actors and $m$ equaling the number of forums. Cell entries can either be 1 or 0 , and represent the presence or absence of a relation (forum membership). For example, cell $X_{i j}=1$ if actor $i$ in set $A$ is a member of forum $j$ in set $F$. This results in a two-mode network with two types of nodes (forums and actors) and ties between nodes representing forum membership.

We describe this network by assessing the number of network ties (forum memberships) per actor category. However, describing a network based on descriptive statistics alone can be problematic. In order to explain the marginal influence of actor categories on activity, other theoretically conceivable processes influencing network structure should be accounted for. The inclusion of these other processes is comparable to the use of control variables in multivariate regression models. In a network where observations are, by definition, nonindependent, such processes can be exogenous or endogenous. For example, looking only at simple distributions of memberships could lead one to the conclusion that public administration actors are much more active than other types of actors. Activity in this regard is understood as actors' likelihood of being a member of multiple forums. However, this conclusion might be invalid, given the potential for interdependent exogenous and endogenous processes in a network. One example of a possible exogenous process is found in the tendency for homophily, which means that similar actors tend to cluster within the same forums. If public administration actors display a much larger degree of homophily than other actor groups, this might explain a large part of their higher number of forum memberships. An example of an endogenous process could be found in a tendency for centralization in the network. This could mean that the network structure tends toward a composition where popular forums with many actors tend to attract more members in a self-reinforcing process. If there is a high tendency towards centralization in the network, the differing distributions of forum membership among actor categories can be in part a result of this process. 
We rely on an exponential random graph model (ERGM) to take into account these different processes, and to model differing activity among actors along with a number of endogenous and exogenous effects expected to have an influence on network structure. Because the probability of any tie depends on the structure of the entire network, the modeling process for dependent data is slightly different from conventional regression analysis, where the outcome variable is expected to be only influenced by exogenous, but not by endogenous processes (Cranmer and Desmarais 2011). Essentially, ERGMs model the probability that a specific network structure is observed given all other potential network structures. Let the random variable $X$ represent a network as a set of tie variables $X_{i j}$, and $x=\left\{x_{i j}\right\}$ denote a realization of $X$. The general form of ERGMs is then a probability distribution of graphs derived as

$$
\operatorname{Pr}(X=x)=\frac{1}{k(\theta)} \exp \sum_{Q} \theta_{Q} z_{Q}(x)
$$

where $\theta_{Q}$ is a parameter associated with a network statistic $z_{Q}(x)$ in a local network configuration $q$ and $k(\theta)$ is a normalizing constant that ensures that the probability distribution sums to 1 (Wang et al. 2013).

The most basic ERGM form is a Bernoulli model that assigns the same probability for every tie (forum membership) to occur independently of all other ties. The probability of a single network $x$ based on a this model is:

$$
\operatorname{Pr}(X=x)=\frac{1}{k} \exp \left\{\theta z_{L}(x)\right\}
$$

Here, $\theta$ is the density (or edge, as in Table 1) parameter controlling the chance for a tie to occur. The network statistic associated with it is the number of ties in the network $z_{L}(x)$ (Wang et al. 2009). Further covariates are then added to the model - as in regression models to test whether they affect the probability of the structure of the network based on theoretical considerations. The covariates can generally be interpreted as conditional log-odds of a tie forming between an actor and a forum, although most terms used to model higher-order 
dependencies are less straightforward in their interpretation. Markov Chain Monte Carlo Maximum Likelihood Estimation (MCMC MLE) is used to estimate the models as the maximum likelihood estimation cannot be obtained analytically (Wang et al. 2013). Table 1 gives an overview of all covariates used in modeling.

\section{[Table 1 about here]}

Testing for goodness of model fit relies on a large number of simulated networks to assess how accurately the overall model predicts characteristics of the network not included in the model. ERGMs were fitted and goodness of fit was assessed using the package xergm (Leifeld et al. 2016) within the R statistical environment (R Development Core Team 2014). For a more in-depth discussion of ERGMs, see Cranmer and Desmarais (2011) and Cranmer et al. (2016).

\section{Analysis}

\section{Size and composition of forums}

The first part of the empirical analysis of the network of forums in Swiss water governance presents the purposes and outputs of the 23 forums and discusses the number and diversity of their membership bases. As shown in Table 2 (column 3), Swiss water forums differ with respect to size (i.e. number of members). On average, Swiss water forums have about 27 members, with a minimum of eight members (SVGW Subcommittee 'Extraction / Storage / Distribution') and a maximum of 98 members (VSA Competence Centre 'Urban Drainage'). Size is relevant as it influences the kind of functions that a forum can adopt (Provan and Kenis 2008; Crona and Parker 2012; Feiock 2013; Fischer and Leifeld 2015): large groups can be useful for developing networks and sharing information, but it is easier for smaller 
groups to take positions on issues and act collectively (Koontz and Johnson 2004). In general, transaction costs of within-group coordination increase with the size of a forum.

\section{[Table 2 about here]}

Forum composition in terms of different types of actors is crucial to understanding how forums contribute to cross-sectoral interaction in Swiss water governance. A heterogeneous set of forum members can be necessary for the solution of certain environmental challenges, but it also increases transaction costs of forum interactions. According to our definition of forums as bodies that integrate actors from different sectors, that is, the public administration, the private sector, and the scientific community, forum composition is assessed in terms of these three categories of actors. In Table 2 (columns 4-6), the cell of the actor type that dominates the respective forum is shaded, and the cell with the maximum value per actor type is framed. On average, more than half of the members are private actors, about one third are public administration actors, and only $10 \%$ are scientific actors. Whereas private actors constitute a majority in 17 forums, scientific actors have a majority in only two forums. Seven forums are composed predominantly by public administration actors, in three cases there is an equal number of public administration and private actors. Thus, scientific actors are clearly in a position of numerical minority, whereas private actors constitute the most frequent actor type.

Among the forums in our sample, there are no strict access rules which would predefine the number and type of actors from different sectors to be included. In most cases, actors aiming to participate in a forum are required to be specialized or at least strongly interested in the issue the forum deals with. In some cases, both active participation and the commitment to basic values is required. Links to the websites of all forums are embedded as hyperlinks in Table 2. 


\section{Individual forums in the Swiss water forum network}

Besides size and composition, forums in our sample vary with respect to their internal structure, the issues they deal with, their purpose, and their outputs. The forum 'Water Agenda 21' consists of a main forum and three working groups. The topics of the three working groups are: river basin management, hydropower, and river restoration. For example, the working group on water basin management is relatively small, including representatives of nine collective actors. Its main goal is to address target conflicts in water management and to identify potential solutions. Apart from facilitating exchange and trust building among the various actors, the working group elaborates overviews of current practices related to water basin management.

The Swiss Water Association (VSA) is an association of professionals in water protection. Its overarching goal is to maintain clean and vital water bodies. Thus, in contrast to Water Agenda 21, it is less focused on target conflicts, but has an explicit advocacy agenda itself. It is composed of a main forum and six sub-forums that have between 17 and 98 members. The sub-forums deal with topics such as micropollutants, urban drainage, and wastewater treatment. The wastewater treatment group, for example, includes 72 actors, and works towards its goal of fostering knowledge exchange by organizing networking events, or by offering courses for the education of professionals dealing with these respective issues. Furthermore, the working group elaborates guidelines for the implementation of national and cantonal legislation with respect to wastewater treatment.

The other two forums with a multi-level structure are the Swiss Society for Water Management (SWV) and the Swiss Society for Gas and Water Industry (SVGW). The SWV has a certain bias towards the hydroelectricity power industry and associated industries, as well as the public owners of these companies. Its water-related sub-forum, the KOHS, deals with water management in the context of flood protection, and includes about 20 members. 
The SVGW, in turn, is an association of actors involved in drinking water supply. Of its numerous working groups, only the ones dealing with issues such as water treatment, extraction, or storage are relevant for this study.

The other six forums have no multi-level structure. Three of them have a scientific orientation: The Swiss Hydrological and Limmnological Society (SGHL), the Swiss Hydrogeological Society (SGH), and the Swiss Hydrological Commission (CHy), which all aim to promote and coordinate Swiss hydrology and to facilitate exchange between science, policy, and practice. For example, the goal of the Swiss Hydrological Commission is to coordinate the interests of Swiss hydrologists, and to represent them in related organizations at the national or international level. Despite their scientific orientations, these three forums also include public administration and private actors.

In the remaining three forums - Infrawatt, the working group on lakeshores of the Swiss Society for Engineering Biology, and the Swiss Water Partnership (SWP) - science is less central. Instead, certain interest groups play a major role as the topics of these forums are tightly connected to certain fields of the private sector (similar to SWV and parts of VSA). The central topic of Infrawatt is extraction of energy from wastewater and drinking water, and hence the forum addresses the specific concerns of water treatment plant operators and the energy production industry. Accordingly, it gathers mostly private actors, though certain public administration actors also participate. The working group on lakeshores focuses on the conservation and restoration of natural lakeshores. It addresses a topic that is particularly relevant to construction companies and construction engineers, but (to a lesser degree) also to scientific and public administration actors. Finally, the SWP concentrates on water challenges in developing and transition countries and, accordingly, attracts a disproportional number of private actors (companies involved in water technology and trade as well as non-profit development cooperation agencies). 


\section{Interactions in the Swiss water forum network}

As argued above, it is important to look not only at individual forums but at the entire network of actors and forums.

\section{[Figure 1 about here]}

Accordingly, Figure 1 shows the two-mode network of all 23 forums and their members. Forums are represented by squares with numbers referring to the number in Table 2. Actors are represented by circles with different shades for the three different societal sectors. Many private actors (light grey circles) belong to the periphery of the network because they are members of only one forum. They are not central in the two-mode network of actors and forums, and are located far away from other actors and other forums. In order to get in contact with other actors in Swiss water policy, they often have to rely on indirect contacts through other actors and forums. By contrast, many cantonal and national-level public administration actors (black circles) appear at the center of the two-mode network graph, and are closely connected to many forums and, as a consequence, to many other actors. This position theoretically allows them to take a strong coordination role within the Swiss water forum network. Scientific actors (dark grey circles) can be found both at the center and at the periphery of the network.

Figure 2 shows the proportion of actors which participate in more than one water forum. Being a member in more than one forum is a basic precondition for an actor to generate interactions across forums. In Figure 2, public administration actors are divided into their different levels and private actors are split up into individuals, firms, and interest groups (according to their different weights in terms of interest aggregation and potential influence). The bars for these more detailed actor categories appear in dark grey, the bars for the societal sectors (aggregated) in light grey. Figure 2 shows that more than half of the public 
administration actors participate in more than one forum. Representatives of cantons are the type of public administration actors with the most forum memberships, as almost $80 \%$ of them are members of at least two water forums. Municipality groups (associations of municipalities), national public administration actors, and single municipalities are markedly less present in forums, but, still, about $50 \%$ of them are members in more than one forum. Scientific actors are slightly less present than public administration actors in general, with about half of them being a member in at least two forums. Less than $30 \%$ of actors from the private sector belong to more than one forum.

\section{[Figure 2 about here]}

Table 3 lists the most central actors, that is, actors that are members in more than five different Swiss water forums. It corroborates the finding that scientific and public administration actors are more active in the Swiss water forums network. The Federal Office for Environment is the most active actor with participation in 17 out of 23 Swiss water forums. At the national level, this actor is formally responsible for many different waterrelated issues. At the cantonal level, large cantons (Zurich, Bern), as well as cantons with many lakes and water courses (Lucerne, Ticino) seem to be more central than other cantons. At the municipal level, the city of Zurich, which is the largest and economically most important city in Switzerland, stands out as a central actor in the Swiss water forum network. In terms of the scientific community, actors specialized in water-related and technical issues in particular are central within the Swiss water forum network. The water research institute Eawag is present in 14 forums, whereas for example universities with a more general focus tend to participate less frequently in water-related forums.

Thus, while private actors are numerically dominant in the network of Swiss water forums, they are not the ones that create interactions across different forums, and thus across different 
water-related issue domains. By contrast, scientific and public administration actors are present in multiple forums at the same time, and thus connect the different water-related issues and actors in Swiss water politics.

\section{[Table 3 about here]}

\section{Exponential random graph model}

Analyzing the relations between forums and their members based on a two-mode ERGM allows for a more in-depth assessment of the activity of the different actor types. Figure 3 summarizes the point estimates (black dots) of the model coefficients together with their 95\% confidence intervals (two-tailed). The model provides a satisfying fit to the data. Figure S1 in the Supplementary Material shows the goodness of fit plots for the models. They indicate how able the model is to simulate networks with characteristics similar to the ones of empirically observed networks. The degree distribution of actors (first mode) is well-simulated by the model; the degree distribution of the forums (second mode) is not perfect, but also tends to approach the empirical distribution (modeling the degree distribution of the forums is harder, given the small number of forums and the two-peaked distribution of the degree of forums between 15 and 196). K-Stars tend to be slightly underestimated by the model, geodesic distances and dyad-wise shared partners are well modelled. Still, the model tends to produce some isolates that are not present in the empirical data.

\section{[Figure 3 about here]}

The model parameters for the activity of public administration, the private sector, and the scientific community capture our main variables of interest. They can be interpreted as the 
likelihood of a network tie (that is, membership of an actor in a forum) for a given actor type, keeping all the other coefficients constant. The strength and direction of the coefficients support our findings based on the descriptive statistics, according to which private actors have a lower probability of being active in many forums, whereas scientific and public administration actors have a higher likelihood.

The model parameter for societal sector mixing captures the likelihood that actors from one sector join a forum that has a large proportion of actors from other sectors, for example because public administration actors want to benefit from scientific knowledge, or because private actors seek access to forums containing many public administration actors with formal decision-making power. The very small effect of this parameter indicates that this mechanism plays a negligible role in the Swiss water forum network. By contrast, the large effect for actor type homophily indicates a strong tendency for actors to join forums that include a large proportion of actors from their own sector.

The parameters for edges, degree range, geometrically weighted degree, and minimum degree of two for the actor mode account for endogenous processes (such as the low likelihood of actors having more than one forum membership) and serve to model the degree distributions of actors and forums. As such, they are not substantively interpreted here.

\section{Discussion}

The main finding from our analysis suggests that whereas private actors are numerically dominant in the network of Swiss water forums, scientific organizations and, most importantly, public administration actors connect the entire network of Swiss water policy forums. The finding that public administration actors occupy central roles in the forum network, and consequently potentially create coordination among actors from different sectors, relates to similar findings in the public administration and governance literatures. 
As compared to traditional schemes of hierarchical decision-making, modern collaborative and polycentric governance systems are characterized by horizontal, bottom-up coordination between different types of actors. However, despite the decreasing importance of formal authority and hierarchical decision-making, government and public administration actors still play special roles in these governance networks (e.g., Fischer 2016). This analysis shows that public administration actors are central actors in a forum network and thereby potentially contribute to interactions across different societal sectors and different water-related issues. In general, existing literature has suggested that public administration actors often engage in network management and metagovernance in order to steer networks and facilitate interactions (Klijn et al. 1995; Sörensen and Torfing 2009). Different tools in collaborative governance are used by public administration actors aiming to solve public problems, especially if a policy extends beyond their core competences, if the policy spans multiple sectors, or if the goal is to increase the legitimacy of a solution (Scott and Thomas 2016; Leifeld and Fischer 2015). Among them, actively connecting other actors is a network management strategy that is often applied by public administration actors, and is also referred to as connective capacity (Edelenbos and Van Meerkerk, 2015), or brokerage (Ingold and Varone, 2012). They can therefore create interactions between actors from different levels of decision-making, of different types, or dealing with different issues (Edelenbos and Van Meerkerk, 2015). The analysis in this paper shows how actors from different societal sectors are connected within forums, and how public administration actors create connections across forums, and thus across different water-related issues. Similarly, Spekkink and Boons (2016), which study networks composed of different "building blocks" show that private actors are responsible for the interactions within these building blocks, whereas public administration actors are bridging across building blocks.

There are good reasons for public administration actors in collaborative and polycentric governance systems to play these roles, both with respect to their capacities and the benefits 
they gather from forums (Mansbridge 2014). On the one hand, public administration actors still possess crucial resources in terms of organizational capacity and formal authority (Feldman and Khademian 2007; Emerson et al. 2012), and therefore often act as founders or main sponsors of forums (Fischer and Schläpfer 2017). On the other hand, public administration actors have a specific interest in creating interactions between actors from other societal sectors, with expertise in different issues, and representing different interests, given that they are often still responsible for decision-making and thus have an interest in fostering mutual understanding and compromises. Furthermore, public administration actors also benefit from their central position in the forum network in terms of accessing knowledge and gather support for their programs and ideas (Bouwen 2004; Fischer and Leifeld 2015). Especially in the Swiss political system, where public administration has to rely on relatively limited resources (Sciarini et al. 2015), this aspect of forums might be crucial for successful decision-making. Yet participating in different forums at the same time and assuming a coordination role in the forum network also bears transaction costs (Lubell et al. 2016). As compared to public administration actors, private sector and scientific actors might be less capable or interested in participating in multiple forums due to high transaction costs.

In addition to the main result related to public administration actors, results of the statistical model also showed that actor type homophily strongly drives forum membership. This means that independently of the activity of different societal sectors, the forum network structure is not characterized by mixing between sectors. In many forums one type of actor dominates in terms of number of members. For example, the Swiss Water Partnership includes actors from public administration, the private sector, and the scientific community, but 87 percent of its members are private actors. More than half of the members of the VSA Competence Centre 'Industry and Trade' are public administration actors, even if private and scientific actors are also represented (see also Table 2). Given the absence of strict access rules for most forums, processes of self-selection based on actor type homophily and the higher activity of scientific 
and state actors rather than formal rules seem to explain forum composition. Thus, while forums create interactions among actors from different societal sectors, the different sectors are not equally represented in all forums. Most forums are dominated by actors from a particular societal sector, and might thus contribute in particular to the specific needs of that sector.

\section{Conclusions}

This analysis sheds light on one of the ways actors interact within polycentric governance systems (Ostrom 2010). Polycentric governance systems are composed of a multitude of venues and many different types of actors that simultaneously participate in these different venues (Lubell 2013). Forums are one specific type of venue whose distinctive feature is that they include actors from different societal sectors such as public administration, the private sector, and the scientific community, and thus facilitate interactions between these sectors (Tortajada 2010b). This article analyzed the patterns according to which actors from different societal sectors participate in forums, and how the participating actors contribute to interactions within and across forums. Answers to these questions have important implications for our understanding of polycentric governance, participation in modern water governance, and the role of different types of actors in these governance systems.

The main messages from this analysis are the following. First, and related to the theme of this special issue, forums are introduced both theoretically and empirically as specific types of venues which foster participation and interactions of actors from different societal sectors. Forums are one way in which different types of private actors as well as scientific organizations get in contact with public administration actors.

Second, the paper explains why it is important to focus not on a single forum alone, but rather on the entire network of actors and forums. Only utilizing such a network perspective it is 
possible to understand how actors which are members in multiple forums can enable interactions between actors which are members in different forums.

Third, the analysis of the 23 forums and its more than 300 actors shows that public administration actors are the ones that connect the different water forums with each other, even though they are clearly outnumbered by other types of actors. The analysis thus also contributes to knowledge on the changing role of government actors in governance systems, in line with similar findings on network management or brokerage. Whereas approaches of collaborative and polycentric governance emphasize the bottom-up and self-organizing character of governance, this paper shows that public administration actors still play a crucial role in these systems.

Further questions related to the functioning and role of forums abound. Most importantly, this analysis did not show whether cross-sectoral interactions within and across forums really lead to better coordination among actors from public administration, the private sector, and the scientific community. The article only demonstrates the potential for better coordination. Furthermore, the activities of many actors included in our analysis are not limited to waterrelated issues, but extend to other issues. This creates a potential for further connections to other related issues. Open questions also remain with respect to actors' motivation for participating in forums, and with respect to the quality of outputs produced by cross-sectoral interactions in forums. The present analysis only provides a simple initial overview of the potential of forums to organize interactions among actors from different societal sectors in polycentric governance systems. 


\section{References}

Adam, Silke, and Hanspeter Kriesi. 2007. "The Network Approach." In Theories Of The Policy Process, ed. Paul A. Sabatier. Boulder, Colorado: Westview Press. 129-154.

Ansell, Chris, and Alison Gash. 2008. Collaborative Governance in Theory and Practice. Journal of Public Administration Research and Theory 18 (4): 543-571.

FOEN (Federal Office for the Environment). 2011. Einzugsgebietsmanagement Leitbild für die integrale Bewirtschaftung des Wassers in der Schweiz. Bern: FOEN.

Bates, Lorraine E., Melissa Green, Rosemary Leonard, and Iain Walker. 2013. The Influence of Forums and Multilevel Governance on the Climate Adaptation Practices of Australian Organizations. Ecology and Society 18 (4).

Berry, Jeffrey M, and Clyde Wilcox. 2015. Interest group society. London: Routledge.

Bochsler, Daniel. 2009. Neighbours or friends? When Swiss cantonal governments cooperate with each other. Regional and Federal Studies 19 (3): 349-370.

Börzel, Tanja, and Thomas Risse. 2010. Governance without state: Can it work? Regulation \& Governance 4: 113-134.

Bouwen, Pieter. 2004. Exchanging access goods for access: A comparative study of business lobbying in the European Union institutions. European Journal of Political Research 43: 337-369.

Cranmer, Skyler J, Philip Leifeld, Scott D McClurg, and Meredith Rolfe. 2016. Navigating the Range of Statistical Tools for Inferential Network Analysis. American Journal of Political Science. online.

Cranmer, Skyler J., and Bruce A. Desmarais. 2011. Inferential Network Analysis with Exponential Random Graph Models. Political Analysis 19: 66-86.

Crona, Beatrice I., and John N. Parker. 2012. Learning in Support of Governance: Theories, Methods, and a Framework to Assess How Bridging Organizations Contribute to Adaptive Resource Governance. Ecology and Society 17 (1): 32-50.

Dür, Andreas, and Dirk De Bièvre. 2007. The Question of Interest Group Influence. Journal of Public Policy 27 (1): 1-12.

Dür, Andreas, and Gemma Mateo. 2013. Gaining access or going public? Interest group strategies in five European countries. European Journal of Political Research 52 (5): 660-686.

Edelenbos, Jurian, and Geert Teisman. 2013. Water governance capacity: The art of dealing with a multiplicity of levels, sectors and domains. International Journal of Water Governance 1: 89-108.

Edelenbos, Jurian, and Ingmar Van Meerkerk. 2015. Connective capacity in water governance practices: The meaning of trust and boundary spanning for integrated performance. Current Opinion in Environmental Sustainability 12: 25-29.

Emerson, Kirk, Tina Nabatchi, and Stephen Balogh. 2012. An Integrative Framework for Collaborative Governance. Journal of Public Administration Research and Theory 22: $1-29$.

Feiock, Richard C. 2013. The Institutional Collective Action Framework. Policy Studies Journal 41 (3): 397-425.

Feldman, Martha S., and Anne M. Khademian. 2007. The Role of the Public Manager in Inclusion: Creating Communities of Participation. Governance 20 (2): 305-324.

Fischer, Manuel. 2016. "Institutions and policy networks in Europe." In Oxford Handbook of Political Networks, eds. Jennifer N. Victor, Mark Lubell and Alex Montgomery. Oxford: Oxford University Press. 833-54.

Fischer, Manuel, and Philip Leifeld. 2015. Policy forums: Why do they exist and what are they used for? Policy Sciences 48 (3): 363-382. 
Fischer, Manuel, and Isabelle Schläpfer. 2017. Metagovernance and policy forum outputs in Swiss environmental politics. Environmental Politics online.

Fischer, Manuel, and Pascal Sciarini. 2015. Unpacking reputational power: Intended and unintended determinants of the assessment of actors' power. Social Networks 42 (0): 60-71.

- 2016. Collaborative Tie Formation in Policy Networks: A Cross-Sector Perspective. Journal of Politics 78 (1): 63-74.

Grigg, Neil S. 2014. Integrated water resources management: unified process or debate forum? International Journal of Water Resources Development 30 (3): 409-422.

Huxham, Chris, Siv Vangen, Christine Huxham, and Colin Eden. 2000. The challenge of collaborative governance. Public Management an International Journal of Research and Theory 2 (3): 337-358.

Ingold, Karin. 2011. Network Structures within Policy Processes: Coalitions, Power, and Brokerage in Swiss Climate Policy. Policy Studies Journal 39 (3): 435-459.

Ingold, Karin, and Philip Leifeld. 2016. Structural and Institutional Determinants of Reputational Power in Policy Networks. Journal of Public Administration Research and Theory 26 (1): 1-18.

Ingold, Karin, and Frédéric Varone. 2012. Treating Policy Brokers Seriously: Evidence from the Climate Policy. Journal of Public Administration Research and Theory 22: 319346.

Jasny, Lorien, and Mark Lubell. 2015. Two-mode brokerage in policy networks. Social Networks 41 (0): 36-47.

Klijn, Erik-Hans, Joop Koppenjan, and Katrien Termeer. 1995. Managing Networks in the Public Sector: A Theoretical Study of Management Strategies in Policy Networks. Public Administration 73 (3): 437-454.

Koontz, Tomas M, and Elizabeth Moore Johnson. 2004. One size does not fit all: Matching breadth of stakeholder participation to watershed group accomplishments. Policy Sciences 37 (2): 185-204.

Leifeld, Philip, Skyler J. Cranmer, and Bruce A. Desmarais. 2016. xergm: Extensions for Exponential Random Graph Models. R package.

Leifeld, Philip, and Volker Schneider. 2012. Information Exchange in Policy Networks. American Journal of Political Science 53 (3): 731-744.

Lijphart, Arend. 1999. Patterns of democracy: Government forms and performance in thirtysix countries. New Haven: Yale University Press.

Lubell, Mark. 2013. Governing Institutional Complexity: The Ecology of Games Framework. Policy Studies Journal 41 (3): 537-559.

Lubell, Mark, Mark Schneider, John T. Scholz, and Mihriye Mete. 2002. Watershed Partnerships and the Emergence of Collective Action Institutions. American Journal of Political Science 46 (1): 148-163.

Lubell, Mark, Jack Mewhirter, Ramiro Berardo, and John Scholz. 2016. Transaction Costs and the Perceived Effectiveness of Complex Institutional Systems. Public Administration Review. Online.

Mansbridge, Jane. 2014. The role of the state in governing the commons. Environmental Science \& Policy 36: 8-10.

Mauch, Corine, and Emmanuel Reynard. 2004. "The Evolution of Water Regime in Switzerland." In The evolution of national water regimes in Europe, eds. Ingrid Kissling-Näf and Stefan Kuks. Dortrecht/Boston/London: Kluwer Academic Publishers. 293-328.

Moss, Timothy, and Jens Newig. 2010. Multilevel Water Governance and Problems of Scale: Setting the Stage for a Broader Debate. Environmental Management 46 (1): 1-6. 
Ostrom, Elinor. 1990. Governing the commons. The evolution of institutions for collective actors. Cambridge: Cambridge University Press.

2010. Polycentric systems for coping with collective action and global environmental change. Global Environmental Change 20 (4): 550-557.

Provan, Keith G., and Patrick Kenis. 2008. Modes of Network Governance: Structure, Management, and Effectiveness. Journal of Public Administration Research and Theory 18: 229-252.

R Development Core Team. 2014. R: A language and environment for statistical computing.

Scholz, John T., and Bruce Stiftel, eds. 2005. Adaptive Governance and Water Conflict, Resources for the Future. Washington DC, USA: RFF Press.

Sciarini, Pascal, Manuel Fischer, and Denise Traber. 2015. Political Decision-Making in Switzerland. The Consensus Model under Pressure. Basingstoke / New York: Palgrave Macmillan.

Scott, Tyler A, and Craig W Thomas. 2016. Unpacking the Collaborative Toolbox: Why and When Do Public Managers Choose Collaborative Governance Strategies? Policy Studies Journal online.

Sörensen, Eva, and Jakob Torfing. 2009. Making Governance Networks Effective and Democratic Through Metagovernance. Public Administration 87 (2): 234-258.

Spekkink, Wouter A. H., and Frank A. A. Boons. 2016. The Emergence of Collaborations. Journal of Public Administration Research and Theory 26(4): 613-630.

Tortajada, Cecilia. 2010a. Water governance: Some critical issues. Water Resources Development 26 (2): 297-307. . 2010b. Water governance: a research agenda. Water Resources Development 26 (2): 309-316.

Van Meerkerk, Ingmar, Jurian Edelenbos, and Erik-Hans Klijn. 2014. Connective management and governance network performance: the mediating role of throughput legitimacy. Findings from survey research on complex water projects in the Netherlands. Environment and Planning C: Government and Policy 33 (4): 746-64.

Wang, Peng, Ken Sharpe, Garry L Robins, and Philippa E. Pattison. 2009. Exponential random graph $\left(\mathrm{p}^{*}\right)$ models for affiliation networks. Social Networks 31: 12-25.

Wang, Peng, Garry Robins, Philippa Pattison, and Emmanuel Lazega. 2013. Exponential random graph models for multilevel networks. Social Networks 35 (1): 96-115. 


\section{Table 1. Modeling covariates}

\begin{tabular}{|c|c|c|}
\hline Parameter name & Network configuration & Interpretation \\
\hline Edges & $\begin{array}{l}\text { Single forum membership (Sum: } \\
628 \text { ). }\end{array}$ & $\begin{array}{l}\text { Baseline probability of forum } \\
\text { membership }\end{array}$ \\
\hline Public administration activity & $\begin{array}{l}\text { Forum memberships of public } \\
\text { administration actors (Sum: 197). }\end{array}$ & $\begin{array}{l}\text { A significant positive effect } \\
\text { indicates a higher likelihood for } \\
\text { public administration actors to be } \\
\text { active in an additional forum, as } \\
\text { compared to other actors. }\end{array}$ \\
\hline Scientific community activity & $\begin{array}{l}\text { Forum memberships of scientific } \\
\text { actors (Sum: } 49 \text { ). }\end{array}$ & $\begin{array}{l}\text { A significant positive effect } \\
\text { indicates a higher likelihood for } \\
\text { scientific actors to be active in an } \\
\text { additional forum, as compared to } \\
\text { other actors. }\end{array}$ \\
\hline Private sector activity & $\begin{array}{l}\text { Forum memberships of private } \\
\text { actors (Sum: 278). }\end{array}$ & $\begin{array}{l}\text { A significant positive effect } \\
\text { indicates a higher likelihood for } \\
\text { private actors to be active in an } \\
\text { additional forum, as compared to } \\
\text { other actors. }\end{array}$ \\
\hline Actor type homophily & $\begin{array}{l}\text { Statistic measuring for each forum } \\
\text { membership to what extent it } \\
\text { contributes to the share of actors } \\
\text { of the same type within the forum } \\
\text { (actor types as in Figure 2). }\end{array}$ & $\begin{array}{l}\text { A significant positive effect } \\
\text { indicates that actors of the same } \\
\text { type have a higher probability of } \\
\text { being members of the same } \\
\text { forum, as compared to actors of } \\
\text { different types. }\end{array}$ \\
\hline Societal sector mixing & $\begin{array}{l}\text { Statistic measuring for each forum } \\
\text { membership to what extent it } \\
\text { contributes to the share of actors } \\
\text { of the three sectors within the } \\
\text { forum. }\end{array}$ & $\begin{array}{l}\text { A significant positive effect } \\
\text { indicates that an additional forum } \\
\text { membership is more likely if it is } \\
\text { by an actor from a different sector } \\
\text { than by an actor from a type } \\
\text { already represented among forum } \\
\text { members. }\end{array}$ \\
\hline Minimum degree 2 , actor mode & $\begin{array}{l}\text { Actor who participate in at least } \\
\text { two forums (Sum: 118). }\end{array}$ & $\begin{array}{l}\text { A significant positive effect } \\
\text { indicates that actors are likely to } \\
\text { be members of more than one } \\
\text { forum. }\end{array}$ \\
\hline Degree range 5 to 70 , forum mode & Global network measure. & $\begin{array}{l}\text { Used to control for degree } \\
\text { distribution of forums. }\end{array}$ \\
\hline $\begin{array}{l}\text { Geometrically weighted }(\alpha=0.5) \\
\text { degree, actor mode }\end{array}$ & Global network measure. & $\begin{array}{l}\text { Used to control for degree } \\
\text { distribution of actors. }\end{array}$ \\
\hline
\end{tabular}


Table 2. List of Swiss water forums and their membership structure

\begin{tabular}{|c|c|c|c|c|c|}
\hline Case nr. & Water forum (incl. weblinks) & $\mathrm{N}$ of members & $\begin{array}{c}\% \text { of state } \\
\text { actors }\end{array}$ & $\begin{array}{c}\% \text { of private } \\
\text { actors }\end{array}$ & $\begin{array}{c}\% \text { of scientific } \\
\text { actors }\end{array}$ \\
\hline 1 & $\underline{\text { Swiss Hydrological and Limnological Society, Board }}$ & 15 & 26.7 & 33.3 & 40 \\
\hline 2 & $\underline{\text { Swiss Hydrogeological Society, Board }}$ & 25 & 28 & 60 & 12 \\
\hline 3 & $\underline{\text { Swiss Hydrological Commission Chy }}$ & 11 & 27.3 & 27.3 & 45.5 \\
\hline 4 & $\underline{\text { Water Agenda } 21 \text { (WA21), General Members }}$ & 22 & 54.5 & 36.4 & 9.1 \\
\hline 5 & WA21 Working Group 'Water Basin Management' & 9 & 44.4 & 44.4 & 11.1 \\
\hline 6 & $\underline{\text { WA21 Working Group 'Hydropower' }}$ & 10 & 30 & 50 & 20 \\
\hline 7 & $\underline{\text { WA21 Working Group 'River Restoration' }}$ & 21 & 33.3 & 57.1 & 9.5 \\
\hline 8 & Swiss Water Association (VSA), Board & 11 & 45.5 & 54.5 & 0 \\
\hline 9 & $\underline{\text { VSA Platform 'Micropollutants' }}$ & 17 & 47.1 & 47.1 & 5.9 \\
\hline 10 & $\underline{\text { VSA Competence Centre 'Water Bodies' }}$ & 61 & 27.9 & 65.6 & 6.6 \\
\hline 11 & $\underline{\text { VSA Competence Centre 'Wastewater Treatment' }}$ & 72 & 40.3 & 56.9 & 2.8 \\
\hline 12 & $\underline{\text { VSA Competence Centre 'Sewer' }}$ & 54 & 27.8 & 70.4 & 1.9 \\
\hline 13 & $\underline{\text { VSA Competence Centre 'Urban Drainage' }}$ & 98 & 31.6 & 64.3 & 4.1 \\
\hline 14 & $\underline{\text { VSA Competence Centre 'Industry and Trade' }}$ & 18 & 55.6 & 38.9 & 5.6 \\
\hline 15 & $\underline{\text { Swiss Society for Water Management (SWV), Board }}$ & 21 & 9.5 & 76.2 & 14.3 \\
\hline 16 & $\underline{\text { SWV Committee for Flood Protection and Water Management 'KOHS' }}$ & 20 & 35 & 50 & 15 \\
\hline 17 & Swiss Water Partnership & 77 & 5.2 & 87 & 7.8 \\
\hline 18 & Infrawatt, Board & 9 & 22.2 & 77.8 & 0 \\
\hline 19 & $\underline{\text { Swiss Society for Gas and Water Industry (SVGW), Board }}$ & 13 & 38.5 & 61.5 & 0 \\
\hline 20 & SVGW Main Committee _Water' & 16 & 62.5 & 31.3 & 6.3 \\
\hline 21 & $\underline{\text { SVGW Subcommittee 'Water Quality and Treatment' }}$ & 9 & 77.8 & 22.2 & 0 \\
\hline 22 & $\underline{\text { SVGW Subcommittee 'Extraction / Storage / Distribution' }}$ & 8 & 50 & 50 & 0 \\
\hline \multirow[t]{2}{*}{23} & 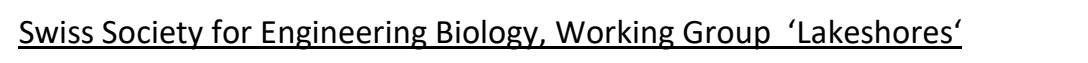 & 11 & 9.1 & 72.7 & 18.2 \\
\hline & Average & 27.3 & 36.1 & 53.7 & 10.2 \\
\hline
\end{tabular}

Shaded areas indicate the sector with the most members in the respective forum. Frames indicate the maximum values for the four variables. Names correspond to either forums' own name in English, or a translation by the authors from German. 
Table 3. Members in more than five Swiss water forums

\begin{tabular}{llc}
\hline Actor & Actor type & N. of forums \\
\hline Federal Office for the Environment & Public administration (national) & 17 \\
Eawag (Aquatic Science) & Scientific community & 14 \\
City of Zurich & Public administration (municipality) & 11 \\
Canton of Berne & Public administration (canton) & 10 \\
Canton of Zurich & Public administration (canton) & 10 \\
EPF Lausanne & Scientific community & 9 \\
Canton of Lucerne & Public administration (canton) & 8 \\
Canton of Ticino & Public administration (canton) & 7 \\
Canton of Valais & Public administration (canton) & 7 \\
Holinger AG & Private sector (firm) & 7 \\
Canton of Fribourg & Public administration (canton) & 6 \\
CSD Engineers & Private sector (firm) & 6 \\
ETH Zurich & Scientific community & 6 \\
\hline
\end{tabular}


Figure 1. Two-mode network of the 23 forums and their members.

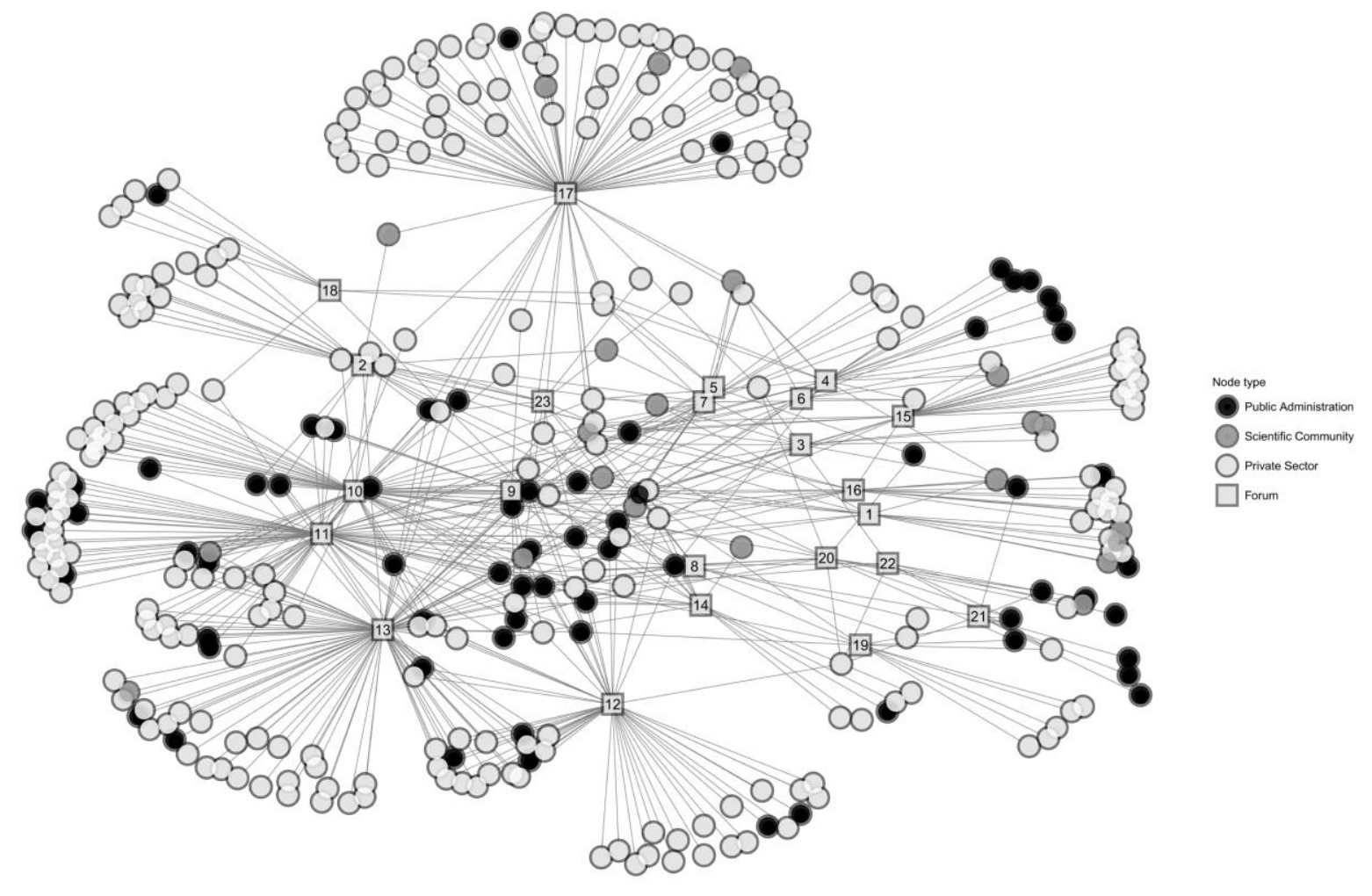


Figure 2. Proportion of actors participating in more than one water forum.

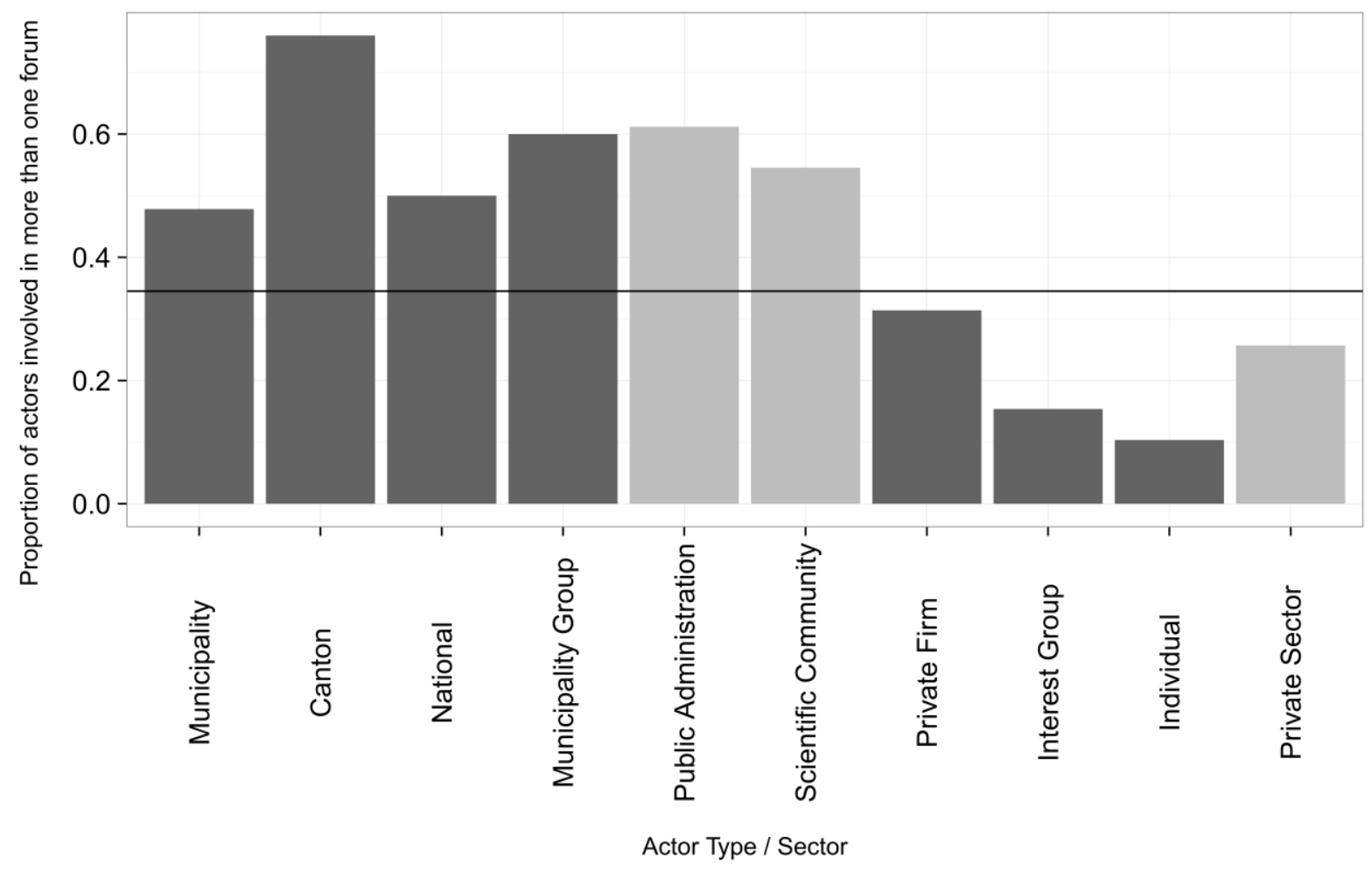


Figure 3. Point estimates and 95\% confidence intervals of model coefficients.

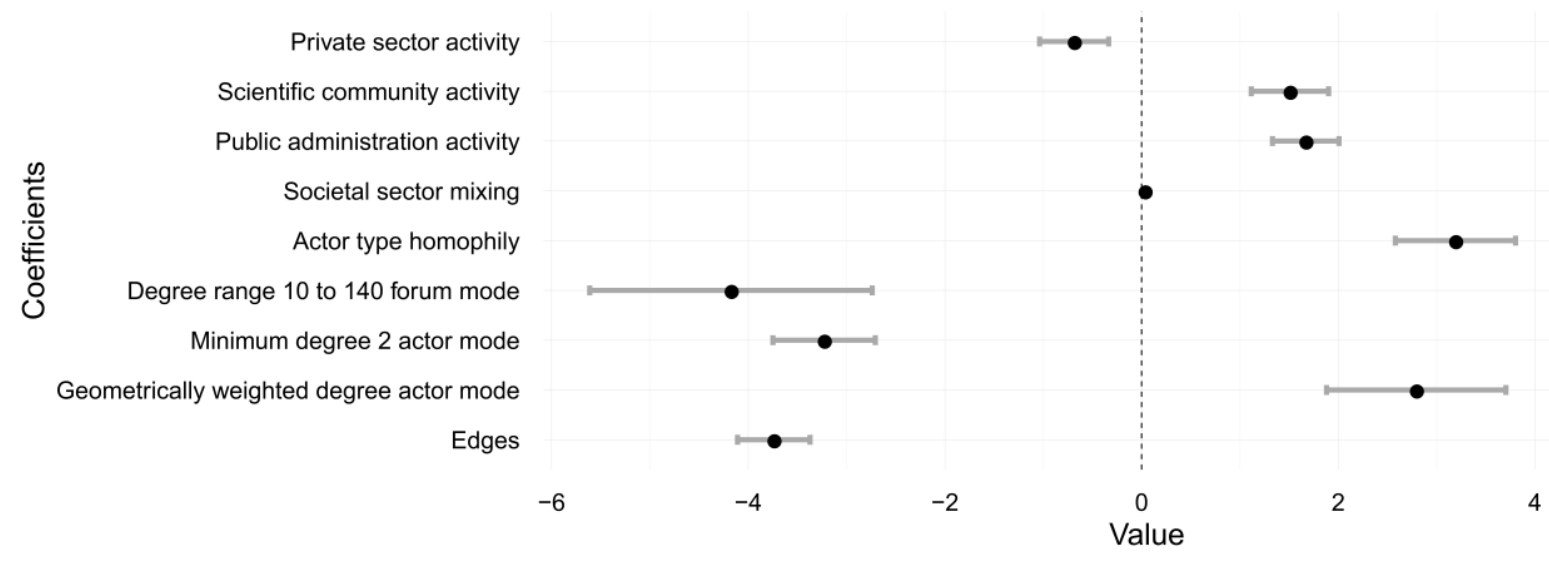


Figure S1. Goodness of fit plots for the ERGM
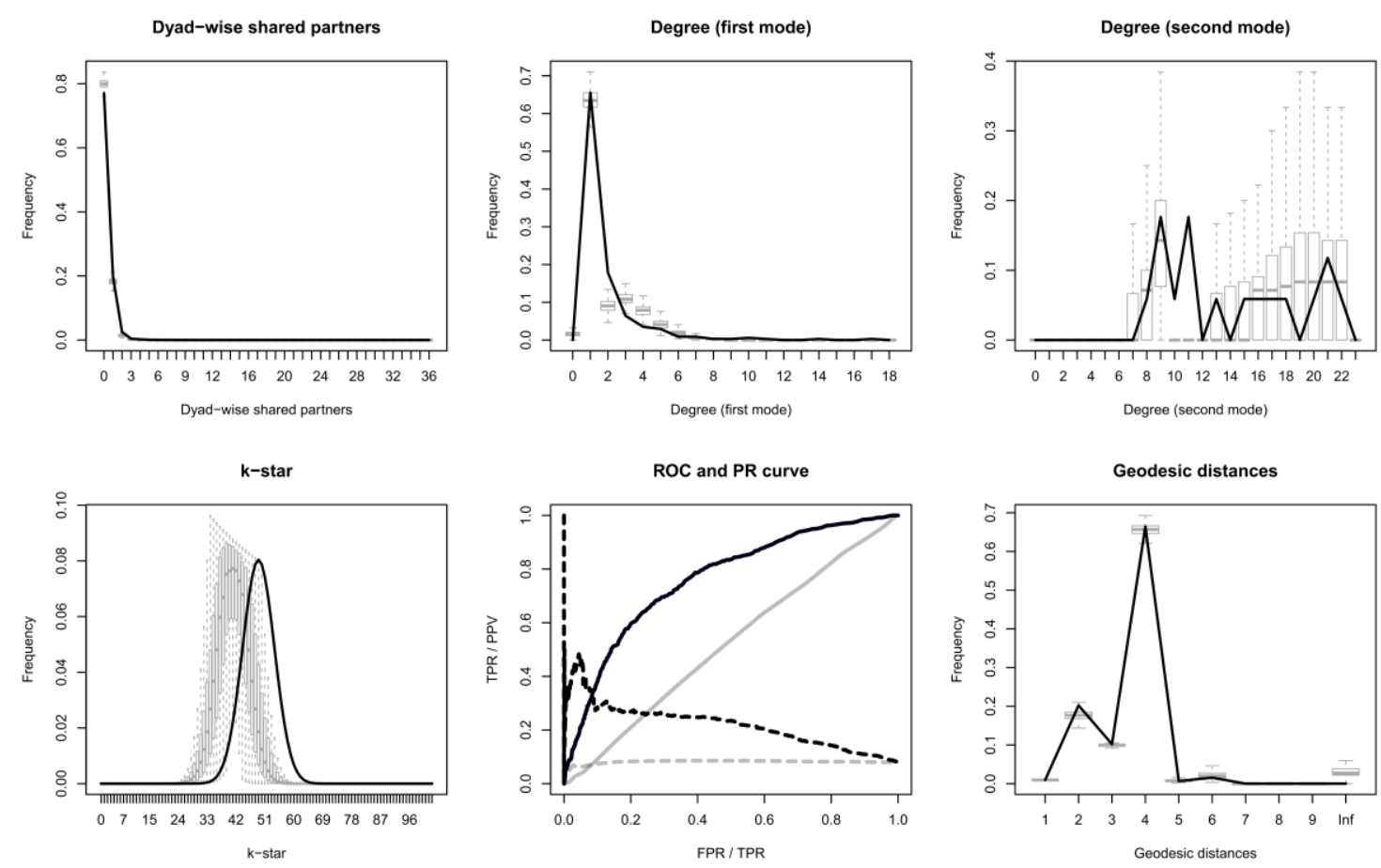